\title{
ESTUDO TÉCNICO E ECONÔMICO DE UM SISTEMA MÓVEL DE EXTRAÇÃO DE ÓLEO ESSENCIAL DE EUCALIPTO
}

\author{
Gisele Aparecida Vivan, Fabrício da Silva Barboza², Maria Laura Gomes Silva da Luz ${ }^{3}$, \\ Carlos Alberto Silveira da Luz ${ }^{4}$, Orlando Pereira-Ramirez5, Mário Conill Gomes ${ }^{6}$, Fátima Cibele Soares
}

(recebido: 17 de novembro de 2009; aceito: 27 de setembro de 2010)

\begin{abstract}
RESUMO: A produção de óleos essenciais apresenta-se crescente no Brasil, especialmente devido aos benefícios que determinadas substâncias contidas nesses podem acrescentar à saúde e à gama de produtos cosméticos, de higiene e fármacos que são originários de seu processamento. Baseado nessas condições e na vasta área no Rio Grande do Sul onde está sendo implantada a cultura do eucalipto o presente estudo busca formas de dinamizar a estrutura econômica da cultura, buscando a geração de novas oportunidades de negócios através da extração do óleo contido na parte foliar do eucalipto, subproduto da indústria papeleira, atual principal interesse econômico da cultura. Partindo desses pressupostos, elaborou-se um projeto conceitual de equipamento móvel que fosse capaz de atender à demanda de processamento da cultura, determinando um fluxograma de processamento e adequando os equipamentos para atender a essa demanda. Posteriormente, avaliou-se a viabilidade técnica e econômica da implantação do sistema de extração móvel para óleo essencial de eucalipto, na região Sul do Rio Grande do Sul, realizando estudos técnicos para o aprimoramento e fechamento de projeto conceitual e análise de viabilidade econômica para determinação das variáveis que discriminam o êxito do projeto. Conclui-se que o projeto conceitual apresenta aspectos vantajosos, em especial quanto à mobilidade, flexibilidade de utilização, minimização de espaços ociosos e uso de água em circuito semifechado. Na análise de viabilidade econômica, os cenários simulados apresentam valores positivos para Valor Presente Líquido, Taxa Interna de Retorno acima da Taxa Mínima de Atratividade e Tempo de Retorno do Capital relativamente reduzido, mesmo para o cenário considerado crítico.
\end{abstract}

Palavras-chave: Viabilidade econômica, resíduos, Eucalyptus.

\section{TECHNICAL AND ECONOMIC STUDY OF A MOBILE SYSTEM FOR EXTRACTION OF EUCALYPTUS ESSENTIAL OIL}

\begin{abstract}
The production of essential oils has become increasing in Brazil, especially considering the benefits that certain substances can add to health and range of cosmetics, toiletries and drugs that originate in its processing. Based on these conditions and in the vast area of the Rio Grande do Sul where it is being implanted the culture of eucalyptus, this study seeks ways to boost the economic structure of culture, seeking to generate new business opportunities through the extraction of oil contained in the leaves Eucalyptus, a byproduct of the paper industry, the current main economic interest of culture. Based on these assumptions, it was elaborated a conceptual design of a mobile equipment able to meet the processing demand of the crop, determining a diagram processing flow and fitting the equipment to meet this demand. Subsequently, it was evaluated the technical and economic feasibility of deploying the mobile extraction system for essential oil of eucalyptus in the southern region of Rio Grande do Sul, conducting technical studies for the improvement and efficiency of the conceptual design and economic feasibility analysis to determine variables that determine the success of the project. It was conclude that the conceptual design has beneficial aspects, especially regarding the mobility, flexibility of use, minimization of empty spaces and water use in semi-closed circuit. In the analysis of economic feasibility, the simulated scenarios showed positive values for Net Present Value, Internal Rate of Return above the minimum rate of attractiveness and capital Payback relatively short, even for the scenarios considered critical.
\end{abstract}

Key words: Economic viability, residue, Eucalyptus.

\footnotetext{
${ }^{1}$ Engenheira Agrícola, Doutoranda em Engenharia Agrícola - Centro de Ciências Rurais - Universidade Federal de Santa Maria - 97105-900 - Santa Maria, RS - xlvivan@yahoo.com.br

${ }^{2}$ Engenheiro Agrícola, Mestrando em Engenharia Agrícola - Departamento de Engenharia Rural - Centro de Ciências Rurais - Universidade Federal de Santa Maria - 97105-900 - Santa Maria, RS - f.barboza@yahoo.com.br

${ }^{3}$ Engenheira Agrícola, Professora Doutora em Engenharia - Departamento de Engenharia Agrícola - Universidade Federal de Pelotas - 96010-610 Pelotas, RS - lauraluz@terra.com.br

${ }^{4}$ Engenheiro Agrícola, Professor Doutor em Engenharia - Departamento de Engenharia Agrícola - Universidade Federal de Pelotas - 96010-610 Pelotas, RS - caluz@terra.com.br

${ }^{5}$ Engenheiro Químico, Professor Doutor em Biotecnologia Ambiental - Departamento de Engenharia Agrícola - Universidade Federal de Pelotas 96010-610 - Pelotas, RS - opr1313@gmail.com

${ }^{6}$ Engenheiro Agrônomo, Professor Doutor em Engenharia de Produção - Departamento de Engenharia Agrícola - Universidade Federal de Pelotas 96010-610 - Pelotas, RS - mconill@gmail.com

7EngenheiraAgrícola,Doutoranda em EngenhariaAgrícola-UniversidadeFederal deSanta Maria-97105-900-Santa Maria, RS-fatimacibele@yahoo.com.br
}

Cerne, Lavras, v. 17, n. 1, p. 23-31, jan./mar. 2011 


\section{INTRODUÇÃo}

Os produtos florestais não madeireiros compreendem uma gama de produtos existentes no ambiente florestal, englobando além das plantas, uma infinidade de seres vivos que compõem o ecossistema local. No caso das plantas, é vasta a variedade de produtos que podem ser obtidos de suas raízes, tronco, cascas, folhas, flores, sementes, frutos, etc. Dentre esses, encontram-se os compostos identificados pelas gomas, resinas, extratos, etc., que vêm apresentando importante potencial para aplicação.

Na categoria dos extratos salientam-se os óleos essenciais, caracterizados como sendo substâncias voláteis extraídas de plantas aromáticas, constituindo matériaprima de grande importância para as indústrias cosmética, farmacêutica e alimentícia. Essas substâncias orgânicas, puras e extremamente potentes são consideradas a alma da planta e alguns destes sendo componentes bioquímicos de ação terapêutica.

A composição química dos óleos (extratos) difere devido à ampla variedade de espécies e subespécies (DAFERERA et al., 2002). Os óleos das folhas de eucalipto, formados por uma complexa mistura de componentes, envolvem de 50 a 100 ou até mais compostos orgânicos voláteis (DORAN, 1991).

No processo de extração de óleo essencial existem diversos métodos, que variam dependendo da matériaprima a ser utilizada e da receita oriunda da extração. No processo de obtenção do óleo de eucalipto, o método mais comum trata-se da extração por destilação, através do processo de arraste a vapor.

O rendimento desse processo varia muito conforme a espécie de planta utilizada, podendo ocorrer perdas nas propriedades sensoriais devido às altas temperaturas, sendo um método geralmente usado para folhas e ervas (VITTI; BRITO, 2003).

No Brasil, a produção de óleo essencial teve início ao final da segunda década do século XX, tendo como base o puro extrativismo de essências nativas, principalmente da árvore do Pau-Rosa (Aniba rosaeodora). Durante a Segunda Guerra Mundial, o país passou a organizar a atividade, consolidando-a basicamente para o atendimento do mercado externo (BRITO, 2002).

No rol das matérias-primas utilizadas no Brasil para extração de óleo essencial, o eucalipto ocupa posição de destaque e a atividade mostra-se crescente em termos de mercado. No mundo, a produção e o comércio de óleos de eucalipto são dominados pela República Popular da China, atual maior produtora de óleos ricos em cineol, com 70\% da produção e comercialização (EMPRESA BRASILEIRA DE PESQUISA AGROPECUÁRIA EMBRAPA, 2009).

Devido à vasta área já ocupada pelos reflorestamentos com eucalipto, o óleo essencial constituise em produto de crescente interesse econômico. Segundo o Instituto Brasileiro de Geografia e Estatística - IBGE (2009) as folhas de eucalipto, utilizadas na fabricação do óleo, totalizaram 48.364 toneladas, sendo o maior produtor nacional o município mineiro de São João do Paraíso, com processamento de 24.938 toneladas de folhas. No Rio Grande do Sul, de acordo com a Associação Brasileira de Produtores de Floresta Plantada - ABRAF (2007) já se encontram implantados 222.245 ha de eucaliptos, o que representa a sétima maior área com a cultura, no País.

A implantação de grandes áreas de reflorestamento traz consigo duas realidades, a expansão de um cenário de monocultura extrativista, contrastando com a possibilidade de desenvolvimento socioeconômico em regiões que vêm apresentando dificuldades de desenvolvimento. Assim, no presente trabalho julgamos conveniente não ser tomado posicionamento quanto à questão cultural e social da região, discutindo somente as questões de caráter técnico e econômico da produção de óleo de eucalipto no local.

Outro fator a ser citado é a questão da degradação ambiental ocasionada pela deposição de elevadas quantidades de folhas em campo, pós-retirada da madeira, em que o acúmulo dessas no sistema solo-água-planta e o elevado teor de compostos químicos de potencial poluidor podem vir a degradar o sistema, agredindo o meio ambiente. Segundo Stape (1997) devido à lenta decomposição das folhas no solo e à proximidade dos eucaliptais dos recursos hídricos, a serapilheira (resíduo do corte) pode ser carreada para cursos d’água, causando efeitos deletérios à biota aquática.

Objetivou-se, no presente trabalho, dimensionar um sistema móvel de captação e processamento das folhas do eucalipto, procurando ajustar a necessidade da rápida coleta do material à possibilidade viável de processamento. Elaborando, após determinação de processos de engenharia, os cenários econômicos da extração, e expondo as perspectivas sociais, econômicas e técnicas do processo.

Cerne, Lavras, v. 17, n. 1, p. 23-31, jan./mar. 2011 


\section{MATERIAL E MÉTODOS}

Inicialmente, o estudo constou da organização de informações e escolha do sistema mais adequado para tornar o empreendimento atrativo. Sendo que, para fins de estudo, realizou-se a subdivisão em Engenharia de Projeto e Engenharia Econômica.

\subsection{Engenharia de Projeto}

O projeto de processamento foi idealizado para operar no extrativismo comercial, em sistema de extração móvel, com funcionamento sobre plataformas a serem atracadas nas áreas de colheita, a fim de realizar o processo de extração do óleo e posterior devolução das folhas ao solo.

Para a realização dos procedimentos relacionados à modulação e construção do equipamento extrator foram definidos pressupostos. Primeiramente, foi definida uma área de abrangência do projeto de 100.000 ha, o que totaliza aproximadamente 1.033.200 toneladas de folha de eucalipto em 7 anos, sendo a colheita distribuída ao longo do período, estarão disponíveis cerca de 147.600 toneladas de folhas por ano para processamento e extração do óleo.

Essas folhas, quando submetidas ao processo de arraste a vapor, apresentam um rendimento médio de
0,7 a 1,5\% de óleo (VITTI; BRITO, 2003). O processo de arraste a vapor é a retirada de óleos essenciais através da emissão de vapor da água, em dornas localizadas em reservatório tipo cesto contendo as partes oleosas da planta. No início do processo, faz-se a vedação da dorna e liberação da passagem de vapor. Esse vapor proveniente da caldeira ascende através do reservatório, levando consigo as pequenas gotículas de óleo, que seguem junto ao vapor de água até o condensador, onde são resfriadas e coletadas para separação. A esquematização do procedimento observa-se na Figura 1.

Realizou-se, posteriormente, a construção de fluxograma com balanço de massa, abrangendo as operações unitárias do processo, e os cálculos de engenharia para dimensionamento dos equipamentos a serem acomodados nas plataformas móveis. O fluxograma com balanço de massa da operação de extração encontrase na Figura 2.

\subsection{Engenharia Econômica}

Na elaboração da análise econômica do projeto, realizou-se o estudo das entradas e saídas de caixa, determinando os índices econômicos e preços mínimos de comercialização do produto.

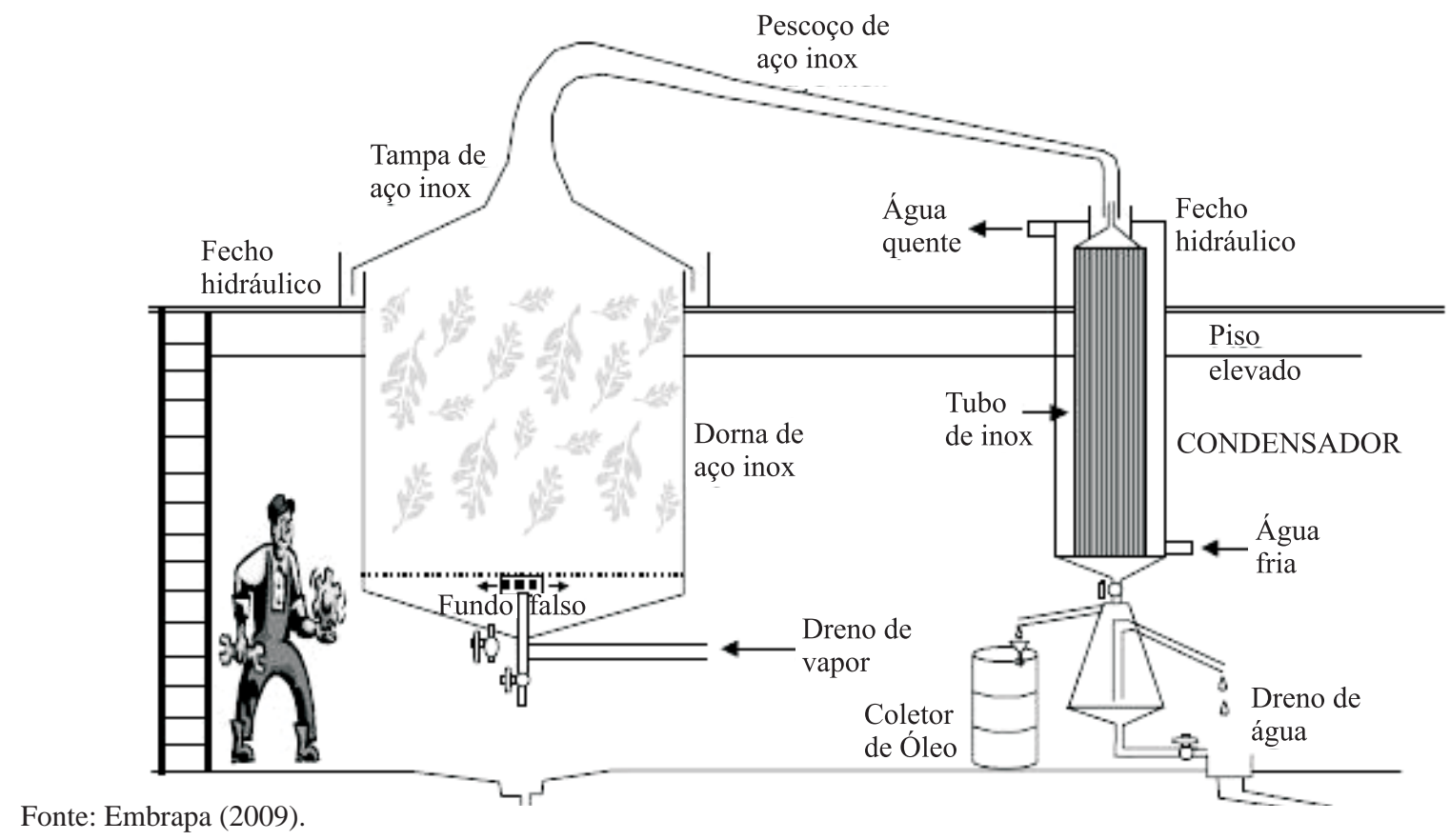

Figura 1 - Esquema de um conjunto destilador para óleos essenciais a arraste a vapor.

Figure 1 - Diagram of a distiller conjunct for extraction of essential oils steam drag. 


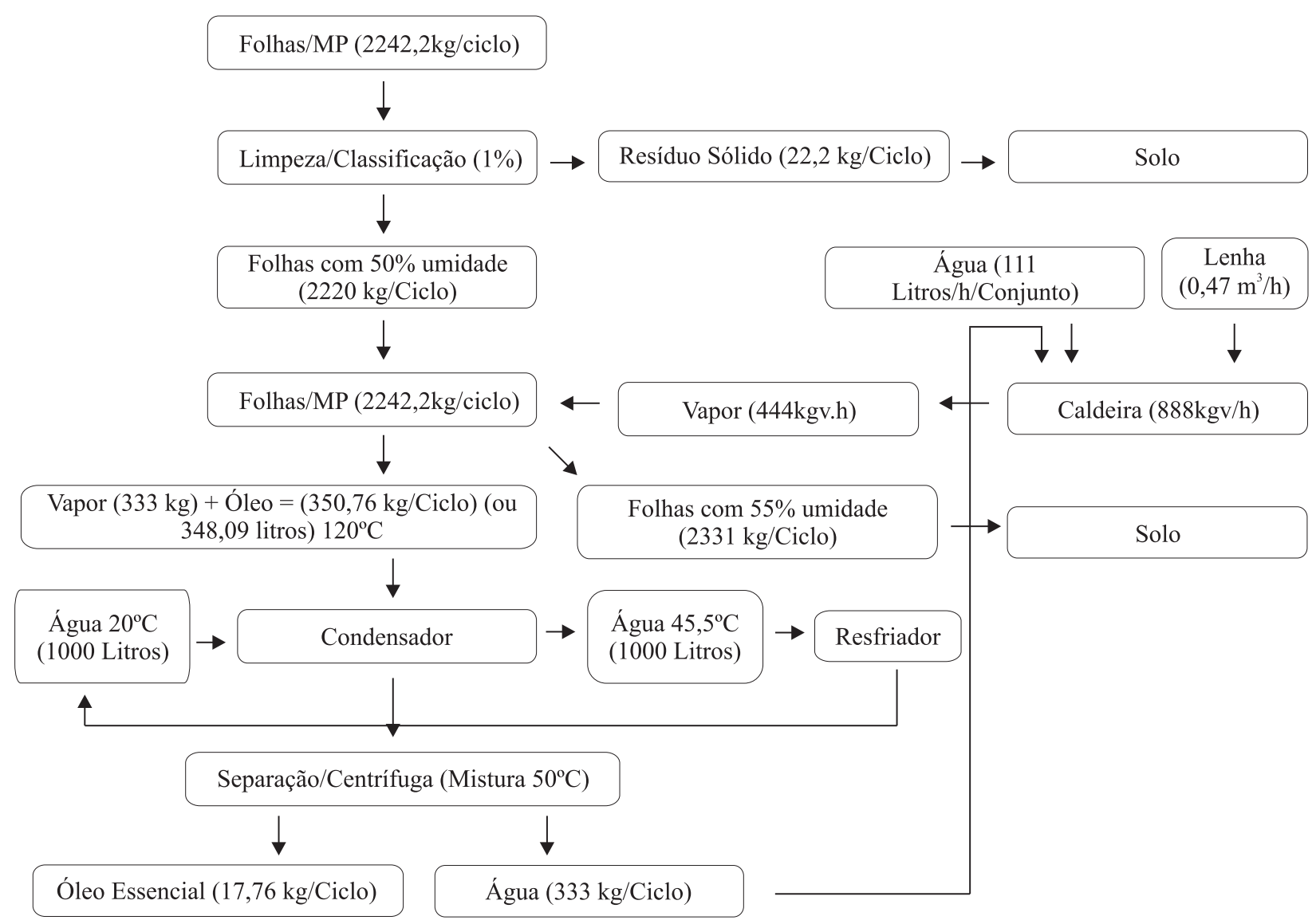

Figura 2 - Fluxograma do processo produtivo, com o balanço de massa do sistema.

Figure 2 - Flowchart of the production process, with the mass balance of the system.

Construiram-se 3 cenários, que representam diferentes condições para o desempenho das vendas e preços do produto, e servirão de base para a realização da análise do fluxo de caixa do projeto.

As variáveis utilizadas para verificação da viabilidade econômica serão o valor presente líquido, a taxa interna de retorno e o tempo de retorno do capital. Segundo Marchetti (1995), as mais importantes medidas de mérito do investimento ou critérios de análise aplicável em análise financeira e econômica são o valor presente líquido (VPL), a taxa interna de retorno (TIR) e tempo de retorno do capital (Payback). Esses foram calculados e apresentam-se nas equações (1), (2) e (3).

$$
V P L=\sum_{j=0}^{n} \frac{X_{j}}{(1+i)^{j}}
$$

$$
\begin{aligned}
& V P L=\sum_{j=0}^{n} \frac{X_{j}}{(1+T I R)^{j}}=0 \\
& I=\sum_{j=1}^{k} X_{j}
\end{aligned}
$$

onde:

$V P L$ é o valor presente líquido (R\$);

$T I R$ é a taxa interna de retorno;

$X j$ é o fluxo de caixa líquido $j(\mathrm{R} \$)$;

I é o tempo de retorno de capital (anos);

$i$ é a taxa mínima de atratividade (TMA);

$n$ é o horizonte de planejamento;

$k$ é o tempo de retorno do capital.

O VPL indica se os retornos obtidos com o investimento são suficientes para compensar os custos operacionais e o investimento realizado em valores de hoje.

Cerne, Lavras, v. 17, n. 1, p. 23-31, jan./mar. 2011 
Para que um investimento seja considerado satisfatório, seu resultado deve ser positivo. A TIR, refere-se à taxa a partir da qual o valor presente torna-se negativo. Para que um investimento seja satisfatório, a taxa interna de retorno deve ser superior à taxa mínima atrativa de retorno. O payback indica o número de anos necessários para que o capital seja integralmente recuperado pelo empresário.

\subsection{Detalhamento técnico do projeto}

\subsubsection{Investimentos}

Considerou-se a divisão do investimento em construção de parte móvel destinada à extração do óleo a campo, sendo composta por treze plataformas e seis truck, destinadas à movimentação do sistema, e um caminhão para a coletas de óleo, resultando em investimento de R \$ 6.459.545,00 e a parte fixa destinada ao processamento do óleo (filtragem e embalagem) representa um investimento de $\mathrm{R} \$ 212.650,00$.

\subsubsection{Depreciações e valor residual}

O horizonte de planejamento aplicado ao projeto foi de 10 anos, considerando-se depreciações de $10 \%$ a.a. para móveis e equipamentos, $20 \%$ a.a. veículos, $4 \%$ a.a. para construções civis e valores residuais de $10 \%$ para móveis e equipamentos, 30\% para veículos e 40\% para as construções civis.

\subsubsection{Custos variáveis}

Incluem material de consumo, 28 funcionários destinados à extração em campo e à hospedagem desses, sendo varíavel dependendo do cenário simulado.

\subsubsection{Custos fixos}

Incluem manutenção, seguros e 14 empregados fixos, totalizando R\$ 630.089,63.

\subsubsection{Vendas}

Foi determinada a comercialização de embalagens em atacado e varejo, com volumes de 10, 25, 100 e 150 ml e 1, 50 e 200 litros, sendo o preço de comercialização variável para cada cenário simulado.

\subsubsection{Despesas variáveis}

Incluem comissões de vendedores (5\% sobre as vendas), despesas financeiras (2\% sobre as vendas) e gasto de logística pós-processamento (R 0,10 por litro).

\subsubsection{Despesas fixas}

Incluem despesas administrativas do sistema (impostos, despesas contábeis...), resultando em R\$ 27.263,38.

\subsubsection{Capital de giro}

Contabilizou-se valor de capital de giro que fornecesse recursos para a operacionalização do processo, num total de R\$ 859.955,42.

\subsubsection{Curva de aprendizagem}

Simularam-se três curvas de aprendizagem, simulando total comercialização no $9^{\circ}, 7^{\circ}$ e $4^{\circ}$ ano, representando respectivamente cenários pessimista, mediano e otimista de inserção no mercado.

\section{RESULTADOS E DISCUSSÃO}

\subsection{Engenharia de Projeto}

O sistema terá características de funcionamento baseado no extrativismo comercial, sendo a melhor adequação encontrada a utilização de sistema de extração móvel. Suas principais vantagens são:

- possibilidade de devolução das folhas de eucalipto já processadas, ao solo;

- menores gastos com transporte de grandes volumes;

- possibilidade de processamento em regiões distantes vistos a independência e mobilidade do conjunto;

- maiores porcentuais de óleo extraído visto o menor tempo para que ocorra o processamento, o que eleva o rendimento obtido.

A estrutura destinada à extração será dimensionada para funcionamento contínuo de 10 horas diárias, com duas dornas por conjunto e volume de dorna de 10.000 litros, sendo necessária a utilização de 13 plataformas de extração para suprir a área de operação. O sistema será estruturado sobre porta-container (plataforma), visando à facilidade operacional. Na Figura 3 evidencia-se a concepção do sistema.

A partir das formulações apresentadas, estabeleceuse que cada 100 ha serão processados por 4 plataformas, com capacidade de processamento individual de 4,3 ha por dia, de forma que as 4 plataformas juntas processarão 17,20 ha/dia, permanecendo na área em média 5,81 dias. Após, serão remanejadas para a próxima área de processamento, considerando-se um raio médio de abrangência do sistema de $100 \mathrm{~km}$. A coleta do óleo será realizada através de caminhão-tanque. Todo o sistema de coleta do óleo encontra-se na Figura 4.

Cerne, Lavras, v. 17, n. 1, p. 23-31, jan./mar. 2011 


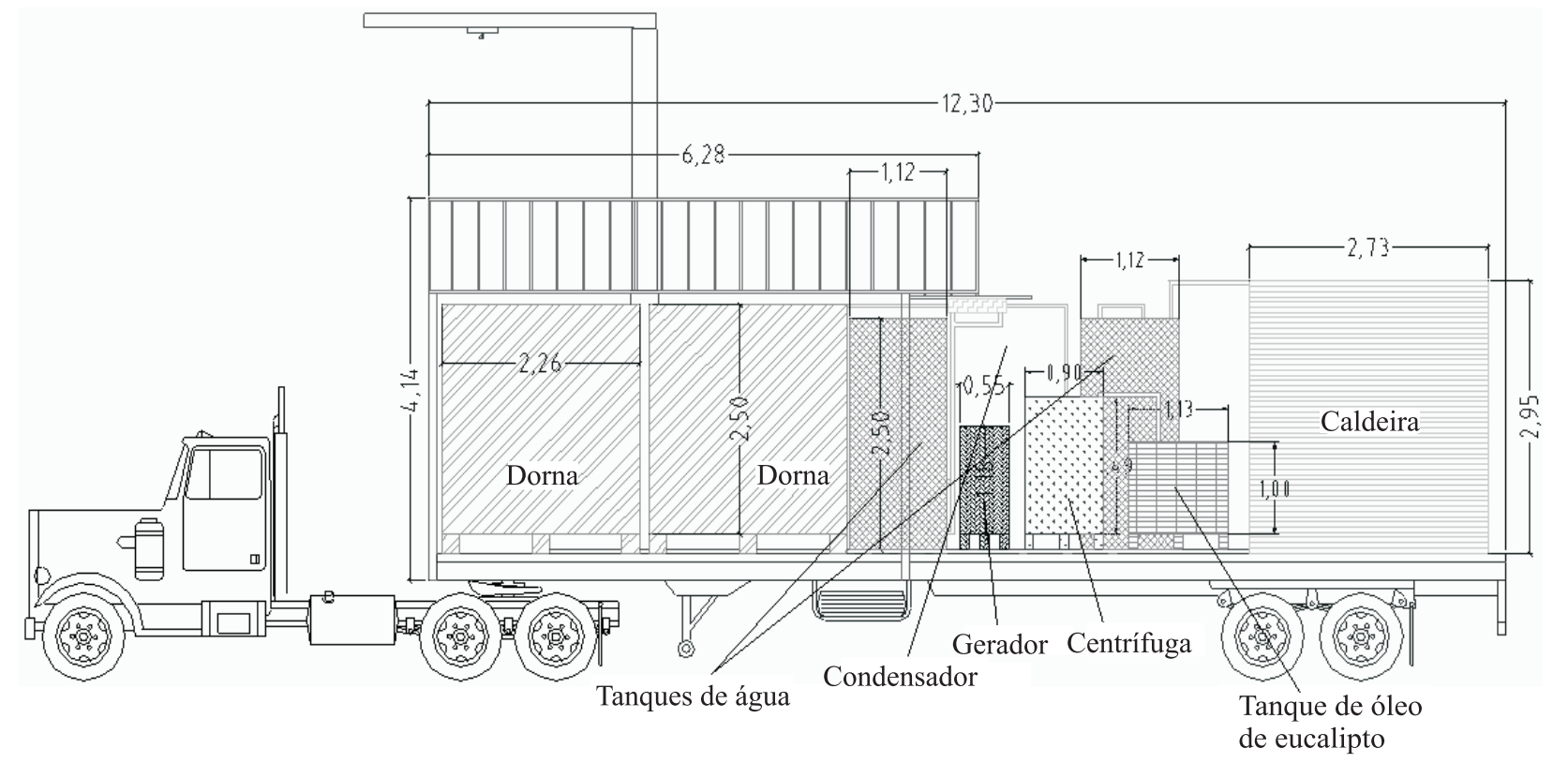

Figura 3 - Plataforma para sistema móvel de extração de óleos essenciais.

Figure 3 - Platform for mobile system for the extraction of essential oils.

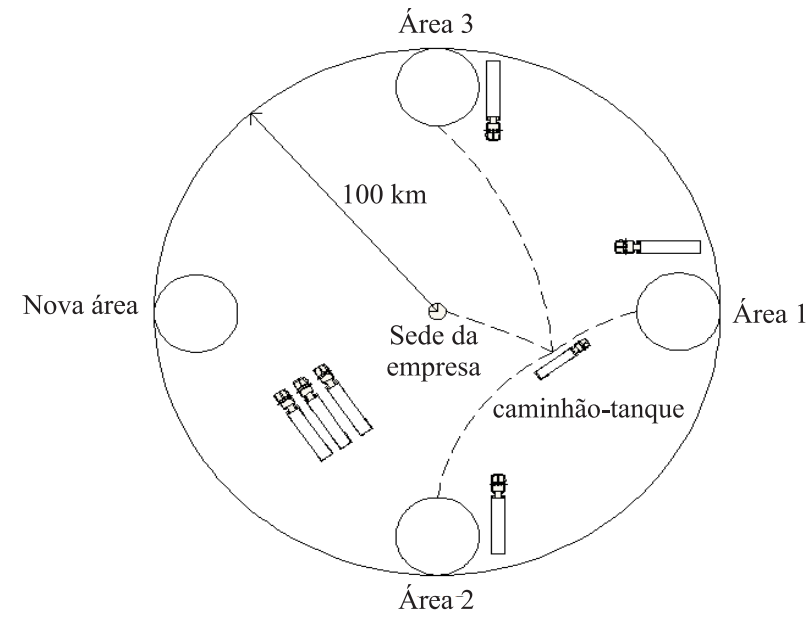

Figura 4 - Representação do funcionamento global do processo de extração.

Figure 4 - Representation of the overall operation of the extraction process.

\subsection{Engenharia Econômica}

Quanto à parte econômica do projeto, foram calculadas as entradas e saídas e simulados três cenários para averiguação das questões que poderiam vir a desestablizar a implantação do sistema. Nos cenários foram variados os valores do preço a ser recebido pelo produto e as curvas de aprendizagem. Os fluxos de caixa para o acionista, para as três situações simuladas estão apresentados na sequência.

Na Tabela 1, apresenta-se o fluxo de caixa do acionista para a situação pessimista, em que a totalidade da produção, representada pelo porcentual de vendas, passa a ser comercializada somente no $9^{\circ}$ ano, e o preço de comercialização simulado foi de $\mathrm{R} \$ 15,00$, por litro do produto. Esse cenário prevê dificuldades de inserção no mercado principalmente por dois entraves: queda geral de preços e fidelidade das empresas consumidoras pelas atuais fornecedoras.

Na Tabela 2 apresenta-se o fluxo de caixa para uma situação mediana, em que a totalidade da produção passa a ser comercializada a partir do $7^{\circ}$ ano, e o preço de comercialização simulado foi de $\mathbf{R} \$ 20,00$ por litro de óleo de Eucalipto.

Na Tabela 3 apresenta-se o fluxo de caixa para a situação otimista, em que a totalidade da produção passa a ser comercializada a partir do $4^{\circ}$ ano, isso é, a partir do $4^{\circ}$ ano tem-se a comercialização total da produção, sendo o preço de comercialização simulado de $\mathrm{R} \$ 25,00$, por litro de óleo de Eucalipto. Esse cenário representa uma inserção positiva no mercado, com uma boa aceitação pelo produto fabricado.

Cerne, Lavras, v. 17, n. 1, p. 23-31, jan./mar. 2011 
Tabela 1 - Fluxo de caixa do acionista para o cenário pessimista, com horizonte de planejamento de 10 anos.

Table 1 - Cash flow of shareholders for the pessimistic scenario, with a planning horizon of 10 years.

\begin{tabular}{|c|c|c|c|c|c|c|c|c|c|c|c|}
\hline \multicolumn{12}{|c|}{ Fluxo financeiro do acionista (1000 R\$) - Cenário Pessimista } \\
\hline Descrição/ANO & $0 \stackrel{\circ}{2}$ & $1^{\mathrm{o}}$ & $2 \stackrel{\circ}{\circ}$ & $3 \stackrel{\circ}{\circ}$ & $4 \stackrel{\circ}{\circ}$ & $5 \stackrel{\circ}{5}$ & $6 \stackrel{0}{6}$ & $7 \stackrel{0}{2}$ & $8 \stackrel{\circ}{2}$ & $9 \stackrel{\circ}{9}$ & $10 \stackrel{\circ}{1}$ \\
\hline \% de Vendas & & $25 \%$ & $25 \%$ & $50 \%$ & $50 \%$ & $75 \%$ & $75 \%$ & $90 \%$ & $90 \%$ & $100 \%$ & $100 \%$ \\
\hline Receita Bruta & & 5.260 & 5.260 & 10.521 & 10.521 & 15.782 & 15.782 & 18.938 & 18.938 & 21.043 & 21.043 \\
\hline (-) Impostos IPI & & 631 & 631 & 1.262 & 1.262 & 1.893 & 1.893 & 2.272 & 2.272 & 2.525 & 2.525 \\
\hline ICMS & & 357 & 357 & 715 & 715 & 1.073 & 1.073 & 1.288 & 1.288 & 1.431 & 1.431 \\
\hline PIS/COFINS & & 192 & 192 & 384 & 384 & 576 & 576 & 691 & 691 & 768 & 768 \\
\hline Receita Líquida & & 4.079 & 4.079 & 8.159 & 8.159 & 12.238 & 12.238 & 14.686 & 14.686 & 16.318 & 16.318 \\
\hline Custo Var. Prod. & & 1.599 & 1.599 & 3.199 & 3.199 & 4.799 & 4.799 & 5.759 & 5.759 & 6.399 & 6.399 \\
\hline Custo Fixo Prod. & & 630 & 630 & 630 & 630 & 630 & 630 & 630 & 630 & 630 & 630 \\
\hline Lucro Bruto & & 1.849 & 1.849 & 4.329 & 4.329 & 6.809 & 6.809 & 8.297 & 8.297 & 9.289 & 9.289 \\
\hline Despesas Variáveis & & 409 & 409 & 818 & 818 & 1.227 & 1.227 & 1.473 & 1.473 & 1.636 & 1.636 \\
\hline Despesas Fixas & & 27 & 27 & 27 & 27 & 27 & 27 & 27 & 27 & 27 & 27 \\
\hline Depreciação & & 754 & 754 & 754 & 754 & 754 & 754 & 754 & 754 & 754 & 754 \\
\hline Despesas Finan. & & 429 & 429 & 381 & 333 & 286 & 238 & 190 & 143 & 95 & 47 \\
\hline Lucro Antes IR & & 229 & 229 & 2.347 & 2.395 & 4.513 & 4.561 & 5.851 & 5.899 & 6.775 & 6.822 \\
\hline IR/Contrib. Social & & 54 & 54 & 774 & 790 & 1.510 & 1.526 & 1.965 & 1.981 & 2.279 & 2.295 \\
\hline Lucro Líq. Após IR & & 175 & 175 & 1.573 & 1.605 & 3.003 & 3.034 & 3.886 & 3.917 & 4.495 & 4.527 \\
\hline (+) Depreciação & & 754 & 754 & 754 & 754 & 754 & 754 & 754 & 754 & 754 & 754 \\
\hline (-) Amortização & & 0,00 & 762 & 762 & 762 & 762 & 762 & 762 & 762 & 762 & 762 \\
\hline (-) Invest. (R\$) + Giro & 7.525 & 0,00 & 0,00 & 0,00 & 0,00 & 0,00 & 0,00 & 0,00 & 0,00 & 0,00 & 0,00 \\
\hline (+) Liber. Financiam. & 6.865 & 0,00 & 0,00 & 0,00 & 0,00 & 0,00 & 0,00 & 0,00 & 0,00 & 0,00 & 0,00 \\
\hline (+) Valor Residual & 0,00 & 0,00 & 0,00 & 0,00 & 0,00 & 0,00 & 0,00 & 0,00 & 0,00 & 0,00 & 861 \\
\hline Fluxo do Acionista & 659 & 930 & 167 & 1.565 & 1.596 & 2.994 & 3.026 & 3.877 & 3.909 & 4.487 & 5.379 \\
\hline
\end{tabular}

Tabela 2 - Fluxo de caixa do acionista para o cenário mediano, com horizonte de planejamento de 10 anos.

Table 2 - Cash flow of shareholders for the intermediate scenario, with a planning horizon of 10 years.

\begin{tabular}{|c|c|c|c|c|c|c|c|c|c|c|c|}
\hline \multicolumn{12}{|c|}{ Fluxo financeiro do acionista (1000 R\$) - Cenário Mediano } \\
\hline Descrição/ANO & $0 \stackrel{\circ}{2}$ & $1^{\circ} \underline{0}$ & 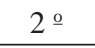 & 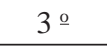 & $4 \stackrel{\circ}{0}$ & $5 \stackrel{\circ}{0}$ & $6 \stackrel{0}{2}$ & $7 \stackrel{\circ}{2}$ & $8 \stackrel{\circ}{2}$ & $9 \stackrel{\circ}{9}$ & 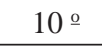 \\
\hline \% de Vendas & & $25 \%$ & $35 \%$ & $50 \%$ & $50 \%$ & $75 \%$ & $95 \%$ & $100 \%$ & $100 \%$ & $100 \%$ & $100 \%$ \\
\hline Receita Bruta & & 5.260 & 7.365 & 10.521 & 10.521 & 15.782 & 19.990 & 21.043 & 21.043 & 21.043 & 21.043 \\
\hline (-) Impostos IPI & & 631 & 883 & 1.262 & 1.262 & 1.893 & 2.398 & 2.525 & 2.525 & 2.525 & 2.525 \\
\hline ICMS & & 357 & 501 & 715 & 715 & 1.073 & 1.360 & 1.431 & 1.431 & 1.431 & 1.431 \\
\hline PIS/COFINS & & 192 & 268 & 384 & 384 & 576 & 729 & 768 & 768 & 768 & 768 \\
\hline Receita Líquida & & 4.079 & 5.711 & 8.159 & 8.159 & 12.238 & 15.502. & 16.318 & 16.318 & 16.318 & 16.318 \\
\hline Custo Var. Prod. & & 1.599 & 2.239 & 3.199 & 3.199 & 4.799 & 6.079 & 6.399 & 6.399 & 6.399 & 6.399 \\
\hline Custo Fixo Prod. & & 630 & 630 & 630 & 6303 & 630 & 630 & 630 & 630 & 630 & 630 \\
\hline Lucro Bruto & & 1.849 & 2.841 & 4.329 & 4.329 & 6.809 & 8.793 & 9.289 & 9.289 & 9.289 & 9.289 \\
\hline Despesas Variáveis & & 409 & 572 & 818 & 818 & 1.227 & 1.554 & 1.636 & 1.636 & 1.636 & 1.636 \\
\hline Despesas Fixas & & 27 & 27 & 27 & 27 & 27 & 27 & 27 & 27 & 27 & 27 \\
\hline
\end{tabular}


Tabela 2 - Continua...

Table 2 - Continued...

\begin{tabular}{|c|c|c|c|c|c|c|c|c|c|c|c|}
\hline \multicolumn{12}{|c|}{ Fluxo financeiro do acionista (1000 R\$) - Cenário Mediano } \\
\hline Descrição/ANO & $0 \stackrel{\circ}{2}$ & $1^{\circ}$ & $2 \stackrel{\circ}{\circ}$ & $3 \stackrel{0}{2}$ & $4 \stackrel{\circ}{4}$ & $5 \stackrel{\circ}{\circ}$ & $6 \stackrel{\circ}{2}$ & $7 \stackrel{\circ}{7}$ & $8 \stackrel{\circ}{\circ}$ & $9 \stackrel{\circ}{2}$ & $10 \stackrel{\circ}{1}$ \\
\hline Depreciação & & 7540 & 754 & 754. & 754 & 754 & 754 & 754 & 754 & 754 & 754 \\
\hline Despesas Finan. & & 429 & 429 & 381 & 333 & 286 & 238 & 190. & 143 & 95 & 47 \\
\hline Lucro Antes IR & & 229 & 1.057 & 2.347 & 2.395 & 4.513 & 6.218 & 6.679 & 6.727 & 6.775 & 6.822 \\
\hline IR/Contrib. Social & & 54 & 335 & 774. & 790 & 1.510 & 2.090 & 2.247 & 2.263 & 2.279 & 2.295 \\
\hline Lucro Líq. Após IR & & 175 & 722 & 1.573 & 1.605 & 3.003 & 4.127 & 4.432 & 4.464 & 4.495 & 4.527 \\
\hline (+) Depreciação & & 754 & 754 & 754 & 754 & 754 & 754. & 754 & 754. & 754 & 754 \\
\hline (-) Amortização & & 0,00 & 762 & 762 & 762 & 762 & 762 & 762 & 762 & 762 & 762 \\
\hline (-) Invest. (R\$) + Giro & 7.525 & 0,00 & 0,00 & 0,00 & 0,00 & 0,00 & 0,00 & 0,00 & 0,00 & 0,00 & 0,00 \\
\hline (+) Liber. Financiam. & 6.865 & 0,00 & 0,00 & 0,00 & 0,00 & 0,00 & 0,00 & 0,00 & 0,00 & 0,00 & 0,00 \\
\hline (+) Valor Residual & 0,00 & 0,00 & 0,00 & 0,00 & 0,00 & 0,00 & 0,00 & 0,00 & 0,00 & 0,00 & 861 \\
\hline Fluxo do Acionista & 659 & 930 & 713 & 1.565 & 1.596 & 2.994 & 4.119 & 4.4249 & 4.455 & 4.487 & 5.379 \\
\hline
\end{tabular}

Tabela 3 - Fluxo de caixa do acionista para o cenário otimista, com horizonte de planejamento de 10 anos.

Tabela 3 - Cash flow of shareholders for the optimistic scenario, with a planning horizon of 10 years.

\begin{tabular}{|c|c|c|c|c|c|c|c|c|c|c|c|}
\hline \multicolumn{12}{|c|}{ Fluxo financeiro do acionista (1000 R\$) - Cenário Otimista } \\
\hline Descrição/ANO & $0 \stackrel{\circ}{2}$ & $1^{\circ}$ & $2 \stackrel{0}{2}$ & $3 \stackrel{0}{\circ}$ & $4 \stackrel{0}{2}$ & $5 \stackrel{0}{0}$ & $6 \stackrel{0}{0}$ & $7 \stackrel{0}{0}$ & $8 \stackrel{0}{-1}$ & $9 \stackrel{0}{9}$ & $10 \stackrel{\circ}{1}$ \\
\hline \% de Vendas & & $25 \%$ & $50 \%$ & $75 \%$ & $100 \%$ & $100 \%$ & $100 \%$ & $100 \%$ & $100 \%$ & $100 \%$ & $100 \%$ \\
\hline Receita Bruta & & 5.260 & 10.521 & 15.782 & 21.043 & 21.043 & 21.043 & 21.043 & 21.043 & 21.043 & 21.043 \\
\hline (-) Impostos IPI & & 631 & 1.262 & 1.893 & 2.525 & 2.525 & 2.525 & 2.525 & 2.525 & 2.525 & 2.525 \\
\hline ICMS & & 357 & 715 & 1.073 & 1.431 & 1.431 & 1.431 & 1.431 & 1.431 & 1.431 & 1.431 \\
\hline PIS/COFINS & & 192 & 384 & 576 & 768 & 768 & 768 & 768 & 768 & 768 & 768 \\
\hline Receita Líquida & & 4.079 & 8.159 & 12.238 & 16.318 & 16.318 & 16.318 & 16.318 & 16.318 & 16.318 & 16.318 \\
\hline Custo Var. Prod. & & 1.599 & 3.199 & 4.799 & 6.399 & 6.399 & 6.399 & 6.399 & 6.399 & 6.399 & 6.399 \\
\hline Custo Fixo Prod. & & 630 & 630 & 630 & 630 & 630 & 630 & 630 & 630 & 630 & 630 \\
\hline Lucro Bruto & & 1.849 & 4.329 & 6.809 & 9.289 & 9.289 & 9.289 & 9.289 & 9.289 & 9.289 & 9.289 \\
\hline Despesas Variáveis & & 409 & 818 & 1.227 & 1.636 & 1.636 & 1.636 & 1.636 & 1.636 & 1.636 & 1.636 \\
\hline Despesas Fixas & & 27 & 27 & 27 & 27 & 27 & 27 & 27 & 278 & 27 & 27 \\
\hline Depreciação & & 754 & 754 & 754 & 754 & 754 & 754 & 754 & 754 & 754 & 754 \\
\hline Despesas Finan. & & 429 & 429 & 381 & 333 & 286 & 238 & 190 & 143 & 95 & 47 \\
\hline Lucro Antes IR & & 229 & 2.300 & 4.418 & 6.536 & 6.584 & 6.632 & 6.679 & 6.727 & 6.775 & 6.822 \\
\hline IR/Contrib. Social & & 54 & 758 & 1.478 & 2.198 & 2.214 & 2.230 & 2.247 & 2.263 & 2.279 & 2.295 \\
\hline Lucro Líq. Após IR & & 175 & 1.542 & 2.940 & 4.338 & 4.369 & 4.401 & 4.432 & 4.464 & 4.495 & 4.527 \\
\hline (+) Depreciação & & 754 & 754. & 754 & 754 & 754 & 754 & 754 & 754 & 754 & 754 \\
\hline (-) Amortização & & 0,00 & 762 & 762 & 762 & 762 & 762 & 762 & 762 & 762 & 762 \\
\hline (-) Invest. (R\$) + Giro & 7.525 & 0,00 & 0,00 & 0,00 & 0,00 & 0,00 & 0,00 & 0,00 & 0,00 & 0,00 & 0,00 \\
\hline (+) Liber. Financiam. & 6.865 & 0,00 & 0,00 & 0,00 & 0,00 & 0,00 & 0,00 & 0,00 & 0,00 & 0,00 & 0,00 \\
\hline$(+)$ Valor Residual & 0,00 & 0,00 & 0,00 & 0,00 & 0,00 & 0,00 & 0,00 & 0,00 & 0,00 & 0,00 & 861 \\
\hline Fluxo do Acionista & 659 & 930 & 1.533 & 2.931 & 4.329 & 4.361 & 4.392 & 4.424 & 4.455 & 4.487 & 5.379 \\
\hline
\end{tabular}

Cerne, Lavras, v. 17, n. 1, p. 23-31, jan./mar. 2011 
Os fluxos de caixa foram determinados a partir dos dados das entradas e saídas de capital do sistema, e da tomada de decisão pelo uso total de capital financiado para pagamento dos investimentos e de próprio para capital de giro. Observou-se que, para todas as situações estudadas esse se manteve positivo ao longo do horizonte de planejamento, sendo correta a determinação dos índices econômicos para a análise da viabilidade e propensão de êxito do projeto.

\subsection{1 Índices econômicos}

Os índices econômicos VPL, TIR e payback representativos das situações pessimista, mediana e otimista apresentam-se na Tabela 4.

Tabela 4 - Determinação dos índices econômicos dos cenários estudados.

Table 4 - Determination of economic indices of the studied scenarios.

\begin{tabular}{lccc}
\hline Cenário & Pessimista & Mediano & Otimista \\
\hline TMA & $12,00 \%$ & $12,00 \%$ & $12,00 \%$ \\
Investimentos (1000 R\$) & 7.525 & 7.525 & 7.525 \\
VPL (1000 R\$) & 8.748 & 22.473 & 42.204 \\
Payback (anos) & 5,0 & 3,0 & 2,0 \\
TIR & $28,78 \%$ & $48,58 \%$ & $76,16 \%$ \\
\hline \multirow{2}{*}{ TIR > TMA } & Projeto & Projeto & Projeto \\
& Atrativo & Atrativo & Atrativo \\
\hline
\end{tabular}

\subsubsection{Preço Mínimo}

Determinou-se o preço mínimo de comercialização, isso é a determinação do valor mínimo para que ocorra a equivalência entre os valores da TMA e a TIR, sendo esses para as situações pessimista, mediana e otimista, respectivamente de $\mathrm{R} \$ 10,29, \mathrm{R} \$ 9,22, \mathrm{R}$ \$ 8,54.

\section{CONCLUSÕES}

A parte construtiva do projeto apresenta-se inovadora para extração de óleos essencial de Eucalipto, tendo como diferenciais:

- mobilidade: que possibilita o não deslocamento de grandes quantidades de material volumoso e deposição das folhas pós-processo novamente em campo;

- flexibilidade: o arraste a vapor pode ser o método de extração de óleo utilizado em vasta gama de culturas;
- economia: a maximização no reaproveitamento da água no processo, através do uso de circuito semifechado e minimização de espaços ociosos, com arranjo dos equipamentos sobre o porta-container.

Através da análise da viabilidade econômica conclui-se que o projeto apresenta resultados atrativos em todos os cenários simulados, com preços mínimos de comercialização bastante competitivos.

\section{REFERÊNCIAS}

\section{ASSOCIAÇÃO BRASILEIRA DE PRODUTORES DE FLORESTA PLANTADA. Disponíveis em: <http://www. abraflor.org.br/>. Acesso em: 10 set. 2009.}

BRITO, J. O. Goma-resina de pinus e óleos essenciais de eucalipto: destaques na área de produtos florestais nãomadeireiros. Piracicaba: IPEF, 2002.

DAFERERA, D. J.; TARANTILIS, P. A.; POLISSIOU, M. G. Characterization of essential oils from lamiaceae species by fourier transform raman spectroscopy. Journal of Agriculture and Food Chemistry, Athenas, 2002.

DORAN, J. C. Commercial sources, uses, formation, and biology. In: BOLAND, D. J.; BROPHY, J. J.; HOUSE, A. P. N. Eucalyptus leaf oils: use, chemistry, distillation and marketing. Melbourne: Inkata, 1991. p. 11-28.

\section{EMPRESA BRASILEIRA DE PESQUISA}

AGROPECUÁRIA. Disponível em: <http://www.cnpso. embrapa.br/>. Acesso em: 5 ago. 2009.

\section{INSTITUTO BRASILEIRO DE GEOGRAFIA E} ESTATÍSTICA. Disponível em: <http://www.ibge.gov.br/ busca>. Acesso em: 9 jul. 2009.

\section{MARCHETTI, V. Risco e decisão em investimento produtivo. Porto Alegre: UFRGS, 1995.}

STAPE, J. L. Planejamento global e normatização de procedimentos operacionais da talhadia simples em Eucalyptus. IPEF, Piracicaba, v. 11, n. 30, p. 51-62, 1997.

VITTI, A. M. S.; BRITO, J. O. Óleo essencial de eucalipto. Piracicaba: ESALQ, 2003. 26 p. (Documentos florestais, 17). 